\title{
Trading Activity and Price Volatility in the Municipal Bond Market
}

\author{
Chris Downing and Frank Zhang*
}

August 7, 2002

* The authors thank Darrell Ashton and Gillian Burgess for excellent research assistance, and Jim O'Brien, Dan Covitz, Mike Gibson, Song Han, Paul Harrison, Nellie Liang, Matt Pritsker, Steve Sharpe, Pat White, and Hao Zhou for useful discussions; all remaining errors and omissions are the authors' responsibility. This paper represents the views of the authors and does not necessarily represent the views of the Federal Reserve System or members of its staff. Please address correspondence to (Downing): Federal Reserve Board, Mail Stop 89, Washington, DC 20551. Phone: (202) 452-2378. Fax: (202) 728-5887. E-Mail: cdowning@frb.gov. (Zhang): Federal Reserve Board, Mail Stop 91, Washington, DC 20551. Phone: (202) 452-3760. Fax: (202) 728-5887. E-Mail: xzhang@frb.gov. 


\begin{abstract}
Utilizing a comprehensive database of transactions in municipal bonds, we investigate the volume-volatility relationship in the muni market. We find a positive relationship between the number of transactions and a bond's price volatility. In contrast to previous studies, we find a negative relationship between average deal size and price volatility. These results are found to be robust throughout the sample. Our results are inconsistent with current theoretical models of the volume-volatility relationship. These inconsistencies may arise because current models fail to account for the effects of overall market liquidity on the costs of large transactions.
\end{abstract}




\section{Introduction}

The relationship between the volume of trade in a security and its price volatility has probably always been of interest to market practitioners. More recently, with the availability of large databases of individual transactions, the volume-volatility relationship has received significant attention from the academic community, as well. Previous studies across a wide range of securities markets, including the markets for corporate equity, financial and commodities futures, and foreign exchange, have documented a positive relationship between price volatility and the volume of transactions (see Karpoff (1987) for a review of early theoretical and empirical research). More recent empirical studies have used intra-day data to examine the distinct roles played by different players on the market, and the elements of total trade volume. For example, Daigler and Wiley (1999) test whether the volatility-volume relationship in the futures market depends on the type of trader, concluding that the "general public" - less informed individuals far away from the trading floor - drives the positive volatility-volume relationship found in previous studies. Jones, Kaul and Lipson (1994) find that, after controlling for the number of transactions, trade size offers no additional explanatory power for equity price volatility. ${ }^{1}$ Despite the attention that these issues have received in the academic literature, however, there are relatively few studies of the volatility-volume relationship in the fixed income markets, and none that we are aware of for the municipal bond market.

The object of this article is to make the first comprehensive examination of the volumevolatility relationship in the municipal bond market. The question of the relationship between trade volume and price volatility is of interest in and of itself. ${ }^{2}$ But perhaps more importantly, the municipal bond market offers a different market structure against which to compare and contrast the results on the volume-volatility relationship in other markets. In at least three important respects, the muni market is different from the other markets in which the volatility-volume relation has been studied. These differences stem principally from the fact that the muni market is an over-the-counter market, much like the market for corporate bonds. First, the municipal bond market is less transparent than the equity and futures markets in terms of the availability of basic information on trading activity. For instance, information on individual municipal bond transactions has not been publicly disclosed until very recently. Even now, comprehensive trade volume and price data are only publicly available after a two week lag. This stands in stark contrast to the other markets,

\footnotetext{
${ }^{1}$ Other recent empirical studies include Chan and Fong (2000), Bessembinder and Seguin (1993), Foster and Viswanathan (1993), Gallant, Rossi and Tauchen (1992), and Schwert (1989).

${ }^{2}$ In this paper, we measure trade volume in three ways. We measure the number of trades in a given bond, the total par amount traded in a given bond, and the average size of each trade in a bond.
} 
where transaction disclosure occurs just seconds after the completion of a deal. Second, the municipal bond market is less transparent in terms of information about the bond issuers, because muni bond issuers are not subject to the same financial disclosure requirements as are publicly traded corporations. While publicly traded corporations are required to maintain a quarterly data feed on their activities (10-Q and 10-K reports), most municipal bond issuers typically only release detailed financial information when they float a bond. For smaller muni bond issuers, who tap the credit markets infrequently, official information concerning their financial situation can be very scant, indeed. Finally, the muni bond market is very illiquid compared to the equity, futures, and foreign exchange markets. As we shall discuss in detail later in this paper, even the largest muni bonds are only traded a few times after issuance, while it is not uncommon for shares of a widely held corporation to trade millions of times a day, for example.

The scarcity of information both on trading activity and on the bond issuers implies that information asymmetries between traders on the muni market may be more pronounced than in other markets. Large institutional investors are likely to be much better informed about prices and market volume than are individual investors, since they conduct a larger share of the transactions, and are active in the market on a daily basis. Furthermore, the relatively high costs of acquiring information on bond issuers confers further informational advantages on large institutional investors, who are more likely to have the resources to analyze the credit quality of individual issuers. Hence these investors will be better situated to determine if a transaction is related to a change in fundamental value (e.g., a deterioration in the credit quality of a bond issuer) or if a transaction is being carried out for reasons unconnected to fundamental value (a liquidity trade, such as to re-balance a portfolio). Finally, in a thin market like muni bonds, liquidity is more of a concern to traders than in the other, more liquid, markets. Institutional investors conducting large trades for liquidity reasons may prefer to trade with other equally informed institutional investors on the market, in order to minimize transaction costs and the price impact of the deal. This may help to explain why large investors tend to maintain a broad set of dealer contacts, in order to maximize the probability of finding matching orders for large trades with minimal price impact.

Utilizing a newly developed comprehensive database of secondary market transactions in municipal bonds, we investigate the weekly cross-sectional relationship between price volatility, the number of trades and average trade size. Our results differ in important ways from previous studies. As in many previous studies, we find a positive relationship between the number of trades in a bond, and the bond's weekly price volatility. In contrast, however, we find a negative relationship between average trade size and price volatility, and we find that average trade size retains its explanatory power even after controlling for the number of 
trades in a particular bond. ${ }^{3}$ These results are found to be robust throughout various strata in the data sample, as well as across different time periods and different measures of price volatility.

A rough taxonomy of the theoretical models on the volume-volatility relationship consists of three classes of models: competitive, strategic, and models built on the mixture of distributions hypothesis. Models in the competitive class assume that agents differ in their beliefs or information (Shalen (1993), Harris and Raviv (1993), Kim and Verrecchia (1991), Holthausen and Verrecchia (1990), Grundy and McNichols (1989), and Pfliederer (1984), among others). In these models, the over-response of uninformed investors to an observed increase in trading activity generates a positive volume-volatility relationship. The strategic models also incorporate asymmetric information across agents, but assume that a single informed investor, or small group of informed investors, are able to collude to disguise their trades by making several small-sized trades (see Holden and Subrahmanyam (1992), Foster and Viswanathan (1990), Admati and Pfleiferer (1988), and Kyle (1985), among others). Like the competitive models, the strategic models also predict a positive volume-volatility relation. The third class of models are primarily statistical, built on the mixture of distributions hypothesis (Harris (1987), Tauchen and Pitts (1983), Epps and Epps (1976)). These models predict that, when price volatility is conditioned on average trade sizes and the number of transactions, average trade sizes should have no effect on price volatility (since the number of trades reflects the number of daily information arrivals, the mixing variable). These models have been criticized on the grounds that they are primarily statistical models, as opposed to equilibrium models of economic behavior (see Jones et al. (1994)).

Our results are at odds with the predictions of the competitive and strategic models, in that we find larger average trade sizes depress price volatility. This result is somewhat surprising, given that the structure of the muni market suggests that the asymmetries of information between investors are likely to be even more pronounced than in other markets. However, as we have touched on earlier, the muni market is a very illiquid market. Breaking up a large block of bonds, and searching for buyers for each piece, is relatively costly (both in terms of the direct transaction costs, and the time it takes to find all of the individual bids). Hence, in order to carry out large liquidity-based transactions quickly and at low cost, institutional investors might find it cheaper to transact with other institutional investors.

\footnotetext{
${ }^{3}$ It should be noted that the results of Jones et al. (1994) are not necessarily inconsistent with what we find here. In that paper, the authors applied a strong prior that average trade size should have a positive effect on price volatility, as reflected in their use of one-tailed $t$-tests on the coefficients of average trade size. In fact, for a large number of the firms in their sample, average trade size has a negative coefficient, as we find here. However, based on the information provided in the paper, it is not possible to determine if the negative coefficients are statistically significant.
} 
Since both sides to these transactions are informed, the trades in and of themselves would produce little price impact. Moreover, given the long lags in the dissemination of information about the trades to the rest of the market, uninformed investors would not see the trades and thus would not react. To investigate this conjecture, we split the sample into quartiles based on the trade volume of a bond in a given week (this turns out to be roughly equivalent to splitting the sample based on trade sizes). We find that the negative volume-volatility relationship exists only among transactions in the uppermost quartile of the trade size distribution - big trades by institutional investors of about $\$ 1$ million or more in size each in line with our conjecture. In the lower quartiles, we find that our results are much more consistent with the results found in the equity and futures markets.

When comparing our empirical results with those obtained in the equity, futures, or foreign exchange markets, it is important to bear in mind that our methodology differs somewhat from that typically used in studies of those more actively traded securities. Because muni bonds are traded relatively infrequently, we are unable to construct an unbroken time series of prices for virtually all of the bonds in our raw data sample. Hence, we are forced to use repeated cross-sectional regressions, as opposed to the time-series regressions used in most previous studies. ${ }^{4}$ This affects our results along at least two important dimensions. First, we are unable to examine the full cross-sectional variation in the volume-volatility relationship. We estimate a single coefficient on our volatility variables, as opposed to a coefficient for each issuer (or firm (equities) or class of security (futures, foreign exchange)), as is typical in the other markets. Second, we are unable to control for any persistence in volatility that might be present at the issuer level. This means that, to a certain extent, the significance of our coefficients ought to be interpreted with care, although the large size of our data sample (numbering in the thousands for each weekly regression) mitigates this issue to some extent. Despite these caveats, our findings add to the empirical literature on the volatility-volume relationship by shedding additional light on the differences in the volatilityvolume relation across markets, with implications for the growing theoretical literature on this important topic.

Our paper is organized as follows. Section 2 discusses the dataset at some length, and details the construction of the variables that we use in our empirical investigation. Section 3 presents our empirical results. Section 4 evaluates the robustness of our empirical findings, and section 5 concludes.

\footnotetext{
${ }^{4}$ Lo and Wang (2000) and Brennan and Subrahmanyam (1998) study the cross-sectional properties of trading volume in a different context.
} 


\section{Data Description}

\section{$2.1 \quad$ MSRB Data}

Since 1997, the municipal bond industry has operated under a mandatory transaction reporting regime overseen by the Municipal Securities Rulemaking Board (MSRB). ${ }^{5}$ All dealerto-dealer and dealer-to-customer muni bond transactions are reported to the MSRB after the close of business each day. The MSRB assimilates the daily reports, and after two weeks have passed, releases electronic files containing the information. ${ }^{6}$ Our data are drawn from the comprehensive reports for the period July 2000 through February 2002. ${ }^{7}$

The MSRB transaction reports contain the data fields shown in table 1. Of particular interest to this study are the date information (date of each trade, and for each bond the date of issue and date of maturity), the par amount traded, and the price at which the par amount is traded. The raw files contain a total of 12,309,409 transaction records. However, a defining feature of muni bond market is that it is a very illiquid market. Figure 1 displays some basic information on trading activity in the muni market. Panel A shows a histogram of the number of trades observed for each bond ${ }^{8}$. As can be seen from the figure, approximately one third of the bonds trade only once over the entire period. The bulk of the remaining bonds trade two or three times, with a very long right tail into which falls bonds with many more transaction records.

The very illiquid nature of the muni market suggests that a daily observation interval, as is typically used in studies of price volatility in the equity and futures markets, may prove problematic. Indeed, fully seventy-five percent of the transactions are on single-trade days that is, on days when the bond trades only one time. On these days, one cannot compute a meaningful measure of the intra-day price volatility of the bond in question. A weekly measurement interval improves the situation somewhat, but we are still forced to exclude most of the transactions. As shown in panel B of figure 1, a little over sixty-five percent of the transactions occur in weeks during which the bond trades just one time. Despite this fact, we select the weekly measurement interval, as it seems to strike a reasonable balance between our need for multiple price observations in order to compute a measure of price volatility, and

\footnotetext{
${ }^{5}$ Full details on the system are available at http://www.msrb.org/.

${ }^{6}$ This lag was imposed at the request of the major muni bond dealers, purportedly in order to preserve liquidity in smaller issues. It is questionable whether the reporting lag preserves liquidity. In fact, the MSRB has been releasing the comprehensive data with shorter and shorter lags (at initiation, the lag was one month), suggesting that the concerns about liquidity were overblown.

${ }^{7}$ Prior to July 2000, the MSRB released information only for bonds that traded four or more times per day. We have repeated all of our empirical tests using these less comprehensive data. Our conclusions do not change, which is not surprising given the large sample sizes of both datasets.

${ }^{8}$ This graph is based on trades that are sales to customers on the secondary market.
} 
the requirement that the prices going into the volatility measure be conditioned on nearly the same information set.

In constructing the data sample used in our subsequent empirical analysis, we impose the following screening criteria. First, we restrict our attention to transactions that are sales to customers (trades that occur at the dealers' ask prices), in order to eliminate the possibility of bid-ask bounce effects. Second, we eliminate trades that occur on or before the underwriting syndicate settlement date (i.e., keeping only secondary market trades), focusing exclusively on arms-length transactions between dealers and investors. These restrictions reduce the number of data records to 5,616,779. Third, since we are interested in price volatility, we discard those bonds that are traded only once from the analysis. ${ }^{9}$ Fourth, in order to improve the signal-to-noise ratio in our volatility measure, we impose the requirement that a bond trade at least four times during the week. This results in our regressions having higher $R^{2}$ measures relative to regressions including data constructed with fewer observations per week, but does not otherwise change our basic results. ${ }^{10}$ Fifth, bonds maturing in less than one year are also discarded. Finally, to each of the data records we match additional descriptive information obtained from Bloomberg. For each CUSIP, we add the rating of the bond when it was issued, information on the structure of the bond (e.g., whether the bond is callable or contains sinking fund provisions, or if the bond is insured), the issue size, and data on the nature of the issuer (e.g., if the security is a general obligation or a revenue bond). After applying our screening filter, and match-merging the descriptive information that is available from Bloomberg, our final estimation dataset contains 219,902 bond-week observations.

\subsection{Univariate Statistics}

Since the goal of this article is to study the relationship between price volatility and trading volume on the muni market, the first task at hand is to construct a measure of price volatility. In the subsequent empirical exercises, the primary measure of price volatility that we use is the scaled price range: the difference between the highest and the lowest prices during a week, this difference divided by the weekly average price. Range-based measures of price volatility have a long history in the finance literature (see Garman and Klass (1980), Parkinson (1980), Beckers (1983), and Ball and Torous (1984), among others). Intuitively, the price range is

\footnotetext{
${ }^{9}$ It should be noted that, in principle, one could also examine classes of bonds in order to bring these singletrade bonds under consideration. However, this approach raises a host of issues concerning the comparability of different bond structures, so we focus instead on bonds for which we have multiple observations. Another alternative is to examine portfolios, but this requires unbroken price series for the securities in the portfolios, making it an unsuitable technique for bond price data.

${ }^{10}$ We have carried out extensive sensitivity analysis of the choice of this threshold. We have re-run our analysis using cutoffs ranging from two to ten trades, and none of our results change in a material way.
} 
a better measure of intra-week price volatility than variables derived from closing prices or returns, since it can better capture the price variation within the week. Range is also less noisy than many other volatility measures, such as those based on returns, because there are less restrictions involved in constructing the measure.

More formally, let $P_{i}^{\max }(t)$ and $P_{i}^{\min }(t)$ denote the maximum and minimum observed prices for bond $i$ during week $t$, respectively, and let $\bar{P}_{i}(t)$ denote the average price. Our dependent variable is given by:

$$
S_{i}(t)=\frac{100}{\bar{P}_{i}(t)}\left(P_{i}^{\max }(t)-P_{i}^{\min }(t)\right) .
$$

We scale the price ranges by the inverse of average price so that a given price change will be given greater weight if the bond is discounted, and vice-versa. The other weekly variables in our study are constructed based on the daily series for each variable. Specifically, weekly trading volume and the number of trades per week are defined as the sums of their respectively daily counterparts, and the weekly average trade size is given as the weekly trading volume divided by the number of trades during the week.

The first row of table 2 displays the unconditional means and standard deviations for the variables used in our analysis, where we have pooled all of the weekly data. The first column displays the univariates for our dependent variable. As the table indicates, on average, the proportional change in price is 1.360 percent with a standard deviation of 1.983 percent, showing that there is a significant degree of cross-sectional and time-series variation in price volatility. We observe an average of 10 trades per week on each bond, with substantial variation reflecting the long right tail illustrated in panel B of figure 1. The average par amount traded is $\$ 2.886$ million per week, with a standard deviation of $\$ 11.87$ million, and the average size of each deal is $\$ 0.429$ million, with a standard deviation of $\$ 1.739$ million. The relatively small average deal size is indicative of the presence of "general public" (i.e., individual) investors, who tend to execute smaller trades than institutional buyers. The small average deal size also reflects the fact that municipal issues tend to be smaller than corporate or agency issues, for example, implying smaller block-sizes in secondary market trading.

The average maturity of the bonds in our sample is almost 18 years, with a standard deviation of 8.8 years, indicating that there is significant variation in the maturity dimension. However, the average bond is just 3.8 years old, with a standard deviation of 3.6 years, suggesting that a large proportion of the observations are trades occurring close to the date on which the bond was issued - which is in line with the conventional wisdom in the muni market that individual investors in muni bonds tend to follow buy-and-hold investment 
strategies. We observe bonds with a wide range of ratings from BBB (lowest investmentgrade) up to AAA, but the majority of the bonds carry the highest rating. ${ }^{11}$ The fact that so many muni bonds carry an AAA rating reflects the prevalence of bond insurance in the muni market. ${ }^{12}$

In order to examine the characteristics of our sample in detail, we stratify the sample along several dimensions. First, we break the sample down into two groups - one containing trades that occur within three months of issue, and the other containing trades that occur later. As can be seen from table 2, the recently issued bonds trade more actively and with smaller average deal sizes than the seasoned bonds. Though there is substantial variation in both variables for each group, these results suggest that general public investors tend to most actively trade in a bond shortly after it is issued.

We next explore the potential interaction of maturity and the volume-volatility relationship with a stratification by maturity. We divide the sample into three sub-samples: "short" maturity bonds, with maturities from one to less than seven years, "medium" maturity bonds, with maturities from seven to less than fifteen years, and "long" maturity bonds, with maturities greater than or equal to fifteen years. As shown in table 2, the short maturity bonds have an average maturity of 4.8 years, the medium maturity bonds have an average maturity of 11.7 years, and the long maturity bonds have an average maturity of 23.1 years. As we would expect based on their lower durations, the average price volatility of the short maturity bonds is much lower than that of the medium- and long-maturity bonds. Interestingly, the long-term bonds trade more actively, with a higher average number of trades per day, and with higher average trade volumes.

As noted earlier, one way the municipal bond market is distinguished from the other fixed income markets is by the prevalence of bond insurance. Some have suggested that the prevalence of bond insurance "commodifies" the muni market to a certain degree, raising the possibility that there might be an important interaction between credit quality, and the volume-volatility relationship. In order to explore this possibility, we stratify the sample based on rating. The univariate statistics in table 2 provide some evidence of liquidity differences among bonds of different credit quality. The lowest rated ('BBB') bonds, appear to be the least liquid, trading in quite small blocks relative to the rest of the market, with an average trade size of just $\$ 0.08$ million, relative to $\$ 0.689$ million for 'AA' and 'A' rated bonds, and $\$ 0.350$ million for 'AAA' rated bonds. The lowest-rated bonds trade an average of 10.7 times per day, compared to 8.7 times per day for 'AA' and 'A' rated bonds and 10.9

\footnotetext{
${ }^{11}$ We convert the alphabetic rating scales to numeric scales with AAA ratings assigned a value of $1, \mathrm{AA}$ ratings a value of 2 , and $\mathrm{BBB}$ ratings a value of 3 . We exclude unrated and lower-rated bonds.

${ }^{12}$ For recent studies of the effects of insurance on muni bond yields see Quigley and Rubinfeld (1991) and Hsueh and Chandy (1989).
} 
times per day for 'AAA' rated bonds.

The muni market is further distinguished from the other fixed income markets by the distinction between general obligation (GO) bonds, which are backed by the full faith and credit of a state or local government (making insured GO bonds close substitutes to Treasury securities, excepting their liquidity differences), and revenue bonds, which more closely resemble corporate bonds in that they are secured by specific revenue streams (e.g., the revenues generated by a toll road). ${ }^{13}$ General obligation bonds are generally viewed as fundamentally more secure than revenue bonds, and account for about a third of outstanding municipal debt. As shown in table 2, GO bonds trade with lower average price volatility than revenue bonds, and with somewhat lower average deal sizes and trade volumes. In addition, GO bonds have an average maturity of 15 years, while revenue bonds have a longer average maturity of 19 years.

Our final stratification separates out bonds that are callable from bonds that are not callable. It is fairly standard in the muni market for bonds with maturities greater than ten years to contain call provisions, most often with ten years of call protection and an initial strike price of $\$ 101$ or $\$ 102$ per $\$ 100$ of principal. As illustrated in table 2 , the average maturity of the "Not Callable" bonds is less than ten years. Moreover, the callable bonds carry higher average coupons, and trade with higher average price volatility, both reflecting the presence of embedded call options. ${ }^{14}$

\section{Estimation Procedures and Empirical Results}

In this section, we study the relationship between price volatility and trading activity in the muni market. We first discuss the estimation methodology, and then present a general picture of the cross-sectional relation between price volatility and trading activity variables such as the number of trades, average trade size, and trading volume. We also examine the volatility-volume relation in the context of a set of corresponding pooled regressions, and test the constancy of the structural relationship over the sample period. Lastly, we explore the potential interaction of the volatility-volume relation and bond characteristics by running separate regressions in sub-samples along the dimensions of age, maturity, rating, revenue-backing, and optionality.

\footnotetext{
${ }^{13}$ Some bonds are both GO and revenue bonds - so-called "double-barreled" bonds. These account for only a tiny fraction of the market, and are excluded from our sample.

${ }^{14}$ Duffee (1998) studies the effects of call options on corporate bond yields.
} 


\subsection{Estimation Methodology}

To examine the cross-sectional relationship between the scaled price range and variables measuring trading activity and bond characteristics, we estimate a series of regressions of the following form:

$$
S_{i}(t)=\gamma+\sum_{j=1}^{J} \alpha_{j} Z_{i, j}(t)+\sum_{k=1}^{K} \beta_{k} X_{i, k}(t)+\varepsilon_{i}(t)
$$

where $i$ ranges over all of the bond issues and $t$ indexes the weeks covered by our sample. In the regression specification (2), $S_{i}(t)$ is the scaled price range for bond $i$ at week $t$, and the $Z_{i, j}(t)$ are variables measuring the trading activity in bond $i$, such as the number of trades, the average trade size, and the par volume traded. The $X_{i, k}(t)$ are controls for bond structure, including issue size, maturity, rating, age, and coupon. Cross-sectional regressions of the general form (2) are repeated each week under different sets of the $Z_{i, j}(t)$, resulting in a set of nested regressions.

The incremental statistical and economic significance of each explanatory variable can be gauged with the following battery of measures: (i) the proportion of weeks in which the variable is statistically significant in the weekly cross-sectional regressions, (ii) the FamaMacBeth $t$-statistics, given by the ratio of the average of the weekly coefficient estimates and the corresponding standard error, which is defined as the standard deviation of the weekly parameter estimates divided by the squared-root of number of weeks (see Fama and MacBeth (1973)), and (iii) the incremental improvement in the adjusted- $R^{2}$ when an explanatory variable is added to the right-hand-side of the regression equation. The first two measures examine the statistical significance of an explanatory variable, while the third measure assesses the economic significance of the relationship between the scaled price range and the explanatory variable.

\subsection{Empirical Results}

As noted above, we use a series of nested regressions to test the cross-sectional relationship between bond price volatility and the number of trades, average deal size, and trading volume. Each regression differs in the set of trading activity variables included on the righthand-side of the regression. We run a total of five regressions. In the first, only the number of trades $(\mathbf{N})$ is included in the specification, in addition to the controls for different bond structures. In the second regression, trade volume (Vol) replaces the number of trades on the right-hand-side of the regression equation. In the third regression, we add average size (Avs) to the first specification, in order to test whether it has any additional information 
beyond that incorporated in the number of trades. In the fourth regression, average size is replaced by trading volume, and in the fifth regression, all three variables - the number of trades, average trade size, and trade volume - are included.

Table 3 reports our main results. One result that stands out is that, as shown by the proportion of weeks that the indicator $1_{t\left(\alpha_{N}\right)>2}$ equals one in the weekly regressions, the number of trades is significantly positive in $100 \%$ of the weekly regressions in the four specifications in which it is included as an explanatory variable. Moreover, the coefficient on $\mathbf{N}$ has a Fama-MacBeth $t$-statistic of 38 in all four regressions, with a coefficient estimate averaging close to 0.023 in all four regressions. These results are in line with the previous findings on the positive volatility-number of trades relationship in other markets. When the number of trades variable is added to the regression specification containing trade volume, the adjusted- $R^{2}$ jumps about forty percent from $10.5 \%$ to $14.8 \%$, underscoring the important link between the number of trades and price volatility.

Another interesting result is that when trade volume is the sole trading activity variable on the right hand side of the regression equation, it is negative and significant in $98.8 \%$ of the weekly regressions, with a Fama-MacBeth t-statistic of -27.921. This result contradicts the positive volatility-volume relationship found in the equity and futures markets (see Karpoff (1987)). This rather surprising result suggests that the volatility-volume relationship is quite different in the fixed income markets than in the equity markets. This may be due to the different trading mechanisms in the equity and fixed income markets. While equity trading takes place in both exchange and dealer markets, the vast majority of trading in the muni bonds are carried out in a dealer market, which is much less transparent and illiquid compared to equity markets, as we discussed at the outset.

The average trade size is found to be significantly negatively related to volatility when it appears as an additional explanatory variable alongside the number of trades. The coefficient estimates on average trade size have a mean value of -0.152 over the period, and are significantly negative in $98.8 \%$ of the weekly regressions. Moreover, the coefficient estimate of the average trade size has a Fama-MacBeth $t$-statistic of -25.548 . The addition of average trade size on the right hand side of the regression also improves the explanatory power of the model: the adjusted- $R^{2}$ increases from $13.1 \%$ in the regression where the number of trades is the only trading activity variable to $15.0 \%$ when both the number of trades and average trade size are included.

When average trade size is replaced by volume, the results are similar. Volume is negative and significant in $98.8 \%$ the weekly regressions, with a Fama-MacBeth t-statistic of -27.997 , and the magnitude of improvement in adjusted- $R^{2}$ is also similar. These results suggests that the number of trades and the average trade size (or volume) contain distinct information, 
which contradicts previous findings that the volatility-volume relation disappears when the number of trades is controlled for (see Jones et al. (1994)).

When both average trade size and volume are added to the number of trades, average trade size is still negative and significant in a majority of the weekly regressions. However, volume is no longer significantly negative in many of the weekly regressions. At the same time, the improvement in adjusted $-R^{2}$ is minimal. This is not surprising, since average trade size and volume are by construction highly correlated. Taken together, these results show that average trade size and volume are interchangeable, and in later sub-sample analysis, we will focus on the regression that features the number of trades and average trade size as the trading activity variables.

The coefficient estimates of the control variables in the regressions are also noteworthy. It is interesting that the issue size is positive and significant in all of the regression specifications. This result could suggest that there are more individual investors involved in larger issues, given the evidence that noise trading tends to increase price volatility (see Daigler and Wiley (1999)).

As expected, years-to-maturity is positive and significant, with a Fama-MacBeth tstatistic around 40 in all five regressions. This result is consistent with the notion that bonds with longer maturity tend to have higher durations. Moreover, longer-term bonds have greater sensitivity to credit conditions and other macro-economic or business cycle factors. Similarly, the coefficient of age has an average estimate around 0.014, and a t-statistic that is about eight times larger than its standard error. Credit worthiness is negatively related to price volatility, as shown by the positive relationship between the "rating" variable, which assigns a bigger number to a lesser credit worthy rating. And lastly, the coupon rate is positively and significantly associated with price volatility. This is due to the fact that high coupon bonds usually are also callable, and so their prices tend to fluctuate more than their non-callable counterparts. More detailed analysis of the relationship between bond attributes and price volatility will be presented later on.

We also examine if our results on the volatility-volume relation stand when we pool all of the bond transaction records together. The main results from the pooled regressions remain the same as in the weekly regressions ${ }^{15}$. The number of trades is positive and highly significant with a t-statistic of around 80 in all of the regressions. The coefficient estimate for the number of trades in the pooled regression is around 0.021, which is very close to the average coefficient estimate from the weekly regressions. Trading volume is negative and highly significant in regressions when it is the only trading activity variable or when it is paired with the number of trades. Similarly, the average trade size is negative and highly

\footnotetext{
${ }^{15}$ To save space, we omit the full details of the results.
} 
significant in all regressions. Moreover, as in the case of weekly regressions, adding the number of trades variable greatly enhances the explanatory power of the regression. As in the case of weekly regressions, trading volume or average trade size retain their incremental explanatory power when the number of trades is controlled for. Lastly, just like in the weekly regressions, when average trade size is already in the line-up of the explanatory variables, adding trade volume does not enhance the explanatory power of the regression.

A natural question is whether there are any structural changes in the volatility-volume relationship over the sample period. To get at this issue, we test the hypothesis that the coefficients of the explanatory variables in the regressions are the same for all weeks during the sample period. The F-statistics for each regression are reported in table 3. The hypothesis that the coefficient estimates are the same across the weeks is clearly rejected by the F-tests for all five regression specifications. ${ }^{16}$

In summary, we have taken a close look at the volatility-volume relation under five different specifications, in both weekly cross-sectional regressions and in pooled regressions. The most striking finding is that the coefficient estimates on average trade size and volume are negative, and that each retains its explanatory power when the number of trades is controlled for. We rejected the hypothesis that the structural relationship between price volatility and our explanatory variables remains constant from week to week over the sample period. Bearing this in mind, in what follows we focus on the weekly cross-sectional regressions.

\subsection{Sub-Sample Evidence}

In order to gain further insight into our main results, as well as to check their robustness, we next consider the volatility-volume relationship in different strata of the data. We split the sample along the age, maturity, rating, bond type, and optionality dimensions. Table 4 presents the empirical results for each sub-sample.

As noted in section 2, one characteristic of the muni market is that newly issued bonds trade more frequently than seasoned bonds. Since most muni bond issuers only release detailed financial information at the time a bond is issued, ceterus paribus the degree of information asymmetry in the market for a particular bond should increase as the bond ages. To explore this possibility, we run our regressions separately for newly issued and seasoned bonds, as defined in section 2. As can be seen in table 4, the number of trades is significantly positive in both sub-samples. Average deal size is significantly negative in all but one $(98.8 \%)$ of the weekly regressions for the seasoned group, while it is significantly negative in $72.9 \%$ of the regressions for the newly issued group. The stronger negative relationship

\footnotetext{
${ }^{16}$ Due to the very large sample size, the critical values of the $95 \% \mathrm{~F}$-tests are all approximately 1.0 .
} 
between volatility and average size in the seasoned sub-sample suggests that as the level of current information available to all investors falls, average deal size increases in importance. In other words, as time goes by, average deal size increases in value as an indicator of the amount of information in the price of a deal. A possible explanation for this result is that institutional (i.e. informed) traders tend to trade seasoned bonds more actively than general public investors. This explanation is also consistent with the generally held view in the muni market that general public investors tend to follow buy-and-hold investment strategies.

We next stratify the data by rating and maturity. The positive relationship between volatility and number of trades and the negative association between volatility and average trade size is generally stronger for longer maturity bonds and higher rated bonds. In particular, unlike sub-samples of AAA and AA/A bonds, the number of trades is significantly positive in only $43.5 \%$ of the weekly regressions for BBB bonds. Moreover, for BBB bonds the coefficient on average size has an average value of 1.240 , and is not significant in any of the weekly regressions (using a one-sided test for a negative coefficient). However, the small average number of observations for the BBB bonds suggests we should exercise caution when interpreting these results. With respect to maturity, the proportion of weeks that the average trade size is significantly negative is only $50.6 \%$ for short term bonds, compared to $82.4 \%$ for the medium term bonds, and $98.8 \%$ for the long term bonds. But again, the result on average size for the short term bonds may not be completely comparable to that of the longer maturity bonds due to the differences in sample sizes. Overall, we interpret these results as suggesting that our main result is robust across differences in rating and maturity.

We also split the sample into sub-samples of GO bonds and revenue bonds, and into callable bonds and non-callable bonds. There do not appear to be any major differences in the results for GO and revenue bonds. Callable bonds exhibit a stronger positive relationship between volatility and the number of trades, as well as a stronger negative relationship between volatility and average size. For non-callable bonds, the number of trades is significantly positive in $64.7 \%$ of weekly cross-sectional regressions, while it is always significantly positive for the callable bonds. And the average deal size is significant and negative in $63.5 \%$ of the weekly regressions for the non-callable bonds, while it is significant and negative in 95.3\% of the regressions for callable bonds. Again, we interpret these results as supportive of our overall findings.

In summary, even though there is some variation across different groups of bonds, the sub-sample results show that our main conclusions are robust: price volatility is generally significantly positively related to the number of trades, and significantly negatively related to average trade size. 


\subsection{Regression Results by Volume}

Regression results from previous sub-sections show that, in contrast to the widely documented volume-volatility relationships in the equity market, the relation between average deal size (or volume) and price volatility are negative on the muni market. What drives the difference in the volume-volatility relation between the muni market and the equity market?

One possible explanation is that, since the muni market is a very illiquid market, finding opposite matching orders is costly in terms of both time spent and the price impact. For big institutional investors trying to execute large liquidity-based transactions, it might be cheaper to trade with other institutional investors, rather than breaking up the block of bonds into small pieces (in order to trade with small individual investors). Since both sides of these big block transactions are informed investors, the trades would produce little price impact. On the other hand, trades involving small individual investors would increase price volatility, due to overreaction of uninformed individual investors, who cannot differentiate liquidity trades from information-based trades.

To shed some light on the validity of this conjecture, we split the weekly data into three sub-samples based on volume: the top quartile, the middle two quartiles, and the bottom quartile. We then analyze the relation between price volatility and volume separately for each sub-sample. ${ }^{17}$ Univariate statistics show that there is substantial variation in the number of trades, trade volumes and average deal sizes across the three sub-samples. For the three sub-samples, the average number of trades per week is $19.127,8.713$, and 4.818 , respectively. The mean volumes of the three sub-samples are 10.678 million, 0.383 million, and 0.086 million, respectively. Similarly, the mean average deal sizes for the top quartile, the middle two quartiles, and the bottom quartile are respectively 1.588, 0.053, and 0.018 million. These results are broadly in line with our conjecture that trades in the top quartile are primarily between big institutional investors, while trades in the other sub-samples involve more individual investors. It is also interesting to note that there are no big difference in average issue sizes across these three sub-samples.

Table 5 reports the weekly regression results for the three sub-samples. The most significant result from these regressions is that the average deal size is significantly and negatively related to price volatility in the top quartile, while it is not negatively significant in either the middle two or the bottom quartiles. Specifically, the average deal size is negative and significant in $85.9 \%$ out of all weekly regressions for the top quartile, while it is negatively significant in only $15.3 \%$ of the weekly regressions in the middle two quartiles, and not negatively significant in any of the weekly regressions for the bottom quartile. Moreover, the sign

\footnotetext{
${ }^{17}$ We split the sample by volume rather than by average trade size because this will give us a consistent price volatility measure for each weekly observation.
} 
of the average weekly coefficient of average deal size changes from negative to positive for the bottom quartile. On the other hand, the number of trades remains positively significant in most of the weekly regressions for all three sub-samples. The regression results for the middle two and the bottom quartile are pretty much in line with what Jones et al. (1994) found on the equity market. Regression results with the number of trades and volume as trading activity variables are similar with what we find in table 5 . On balance, these results seem to support our conjecture that trades between big informed institutional investors dampen price volatility, while trades involving uninformed individual investors increase volatility.

\section{Robustness}

In this section, more robustness checks are performed to evaluate the stability of coefficient estimates over time, the robustness of our empirical results to alternative regression specifications, and the sensitivity of the results to the choice of the price volatility measure. We first examine the stability of our main results over time. We split the sample into two equal time periods, one covering the period from July 2000 to May 2001, and the other from May 2001 to February 2002. In each sub-period, we re-estimate the weekly regressions.

The regression results for the sub-periods are presented in panels $\mathrm{A}$ and $\mathrm{B}$ of table 6 . The sub-period results confirm our findings for the entire sample period. In both sub-periods, the number of trades is always significant and positively related to price volatility. Moreover, the average trade size is, in general, significant and negative, even after number of trades is already included as an explanatory variable. The average size is significant and negative in $97.6 \%$ of the weekly regressions in the first period, and significant and negative in $100 \%$ of the regressions in the second period. Just as in the case of the entire sample, adding average size also increases the average explanatory power of the independent variables. For example, the average adjusted- $R^{2}$ in the first half increases from $13.4 \%$ to $15.4 \%$ when average size is added to the number of trades.

In the next exercise, we study whether adding a new variable, hours, defined as hours between the first and last trades during a week, on the right hand side of the regression equation alters our main empirical findings. This variable is intended as a rough control for the different lengths of time between the trades that make up our price volatility measure, when looking across the bonds in a cross-section, or across the weeks for a given bond. As shown in panel A of table 7, our major conclusions do not change with the inclusion of the hours variable. The number of trades are significantly positive in all the weeks for all regressions, and the average deal size or volume are negative and significant in nearly all $(98.8 \%)$ weekly cross-sectional regressions. However, the hours between the first and 
last trades is positive and significant, and it does improve the explanatory power of the regressions. For example, when hours between the first and last trades is added to the number of trades and the average deal size, the adjusted- $R^{2}$ increases from $15 \%$ to $18.9 \%$. This suggests the length of time between the first and last trades during a week does explain some volatility in bond prices during the week.

Finally, we evaluate the sensitivity of our results to the choice of price volatility measure. In a recent article, Alizadeh, Brandt and Diebold (2001) show that the log range is a measure of price volatility with attractive statistical properties. Principally, the log range appears to be nearly Gaussian, making it a good instrument in quasi-maximum likelihood estimation. In their formulation, the $\log$ range is defined as $\log \left[\log \left(P^{\max }\right)-\log \left(P^{\min }\right)\right]$, with $P^{\max }$ and $P^{\text {min }}$ defined as before. We replicate our regressions using log range defined as above to test whether there are major changes in our results under this alternative price volatility measure. As shown in panel B of table 7, our main conclusions are unchanged under this alternative volatility measure. The number of trades is significantly positive in $100 \%$ of the weekly cross-sectional regressions under all regression specifications. When average deal size or volume are added to the specification, they are significantly negative in all of the weekly regressions.

\section{Conclusion}

In this paper, we made the first comprehensive test of the volume-volatility relationship in the municipal bond market. We found that the number of trades observed over a week is positively associated with the price volatility of a particular bond. However, we found that price volatility is negatively related to the average transaction size, and that the average transaction size retains its explanatory power even when the number of trades is controlled for. These results were found to be robust in different strata of the data, as well as through time. We split the sample into quartiles based on trade volume, and found that the negative volume-volatility relationship is driven principally by trades in the upper quartile of trade sizes. In the lower quartiles, our results were similar to those found in the equity and futures markets.

As noted at the outset, our results are at odds with the predictions of competitive and strategic models of the volume-volatility relationship. When interpreted in the context of the muni market structure, however, a direction for future modeling approaches is indicated. Our results seem to suggest that models of the volume-volatility relation need to take into account overall market liquidity, and how this affects the costs of carrying out large transactions. If market liquidity is very low, as in the muni market, large informed investors may be forced 
to trade with one another, perhaps resulting in a very different relationship between volume and price volatility that predicted by the models extant in the literature. 


\section{References}

Admati, A. R. and Pfleiferer, P.: 1988, A theory of intraday patterns: Volume and price variability, The Review of Financial Studies 1(1), 3-40.

Alizadeh, S., Brandt, M. W. and Diebold, F. X.: 2001, Range-based estimation of stochastic volatility models. Forthcoming in Journal of Finance.

Ball, C. A. and Torous, W. N.: 1984, The maximum likelihood estimation of security price volatility: Theory, evidence, and application to option pricing, Journal of Business 57(1), 97-112.

Beckers, S.: 1983, Variances of security price returns based on high, low, and closing prices, Journal of Business 56(1), 97-112.

Bessembinder, H. and Seguin, P. J.: 1993, Price volatility, trading volume, and market depth: Evidence from futures markets, Journal of Financial and Quantitative Analysis 28(1), 21-39.

Brennan, M. and Subrahmanyam, A.: 1998, The determinants of average trade size, Journal of Business 71, 1-25.

Chan, K. and Fong, W.-M.: 2000, Trade size, order imbalance, and the volatility-volume relation, Journal of Financial Economics 57, 247-273.

Daigler, R. and Wiley, M.: 1999, The impact of trader type on the futures volatility-volume relation, Journal of Finance 54, 2297-2316.

Duffee, G. R.: 1998, The relation between treasury yields and corporate bond yield spreads, Journal of Finance 53(6), 2225-2241.

Epps, T. and Epps, M.: 1976, The stochastic dependence of security price changes and transaction volumes: Implications for the mixture-of-distributions hypothesis, Econometrica 44, 305-321.

Fama, E. F. and MacBeth, J. D.: 1973, Risk, return, and equilibrium: Empirical tests, Journal of Political Economy 81(3), 607-636.

Foster, F. D. and Viswanathan, S.: 1990, A theory of the interday variations in volume, variance, and trading costs in securities markets, The Review of Financial Studies 3(4), 593624 .

Foster, F. D. and Viswanathan, S.: 1993, Variations in trading volume, return volatility, and trading costs: Evidence on recent price formation models, Journal of Finance 48(1), 187-211.

Gallant, A. R., Rossi, P. E. and Tauchen, G.: 1992, Stock prices and volume, The Review of Financial Studies 5(2), 199-242. 
Garman, M. B. and Klass, M. J.: 1980, On the estimation of security price volatilities from historical data, Journal of Business 53(1), 67-78.

Grundy, B. D. and McNichols, M.: 1989, Trade and revelation of information through prices and direct disclosure, Review of Financial Studies 2, 495-526.

Harris, L.: 1987, Transactinos data tests of the mixture of distributions hypothesis, Journal of Financial and Quantitative Analysis 22, 127-141.

Harris, M. and Raviv, A.: 1993, Differences of opnions make a horse race, The Review of Financeial Studies 6(3), 473-506.

Holden, C. W. and Subrahmanyam, A.: 1992, Long-lived private information and imperfect competition, Journal of Finance 47(1), 247-270.

Holthausen, R. W. and Verrecchia, R. E.: 1990, The effects of informedness and consensus on price and volume behavior, Accounting Review 65, 191-208.

Hsueh, L. P. and Chandy, P. R.: 1989, An examination of the yield spread between insured and uninsured debt, Journal of Financial Research 12(3), 235-244.

Jones, C. M., Kaul, G. and Lipson, M. L.: 1994, Transactions, volume, and volatility, The Review of Financial Studies 7(4), 631-651.

Karpoff, J. M.: 1987, The relationship between price changes and trading volume: A survey, Journal of Financial and Quantitative Analysis 22, 109-126.

Kim, O. and Verrecchia, R.: 1991, Market reaction to anticipated announcements, Journal of Financial Economics 30, 273-309.

Kyle, A.: 1985, Continuous auctions and insider trading, Econometrica 53, 1315-1335.

Lo, A. and Wang, J.: 2000, Trading volume: Definitions, data analysis, and implications of portfolio theory, Review of Financial Studies 13, 257-300.

Parkinson, M.: 1980, The extreme value method for estimating the variance of the rate of return, Journal of Business 53(1), 61-65.

Pfliederer, P.: 1984, The volume of trade and the variability of prices: A framework for anlysis in rational expectations equilibria. working paper, Stanford University.

Quigley, J. M. and Rubinfeld, D. L.: 1991, Private guarantees for municipal bonds: Evidence from the aftermarket, National Tax Journal 44(4), 29-39.

Schwert, G. W.: 1989, Why does stock market volatility change over time?, Journal of Finance 44, 1115-1153.

Shalen, C. T.: 1993, Volume, volatility, and the dispersion of beliefs, The Review of Financial Studies 6(3), 405-434.

Tauchen, G. and Pitts, M.: 1983, The price variability-volume relationship on speculative markets, Econometrica 51, 484-505. 
Table 1: MSRB Comprehensive Transaction Reports Data Record Items

\begin{tabular}{|c|c|}
\hline Variable & Description. \\
\hline CUSIP & CUSIP of issue traded. \\
\hline Security Description & Description of issue traded. \\
\hline Dated Date & Dated date of issue. \\
\hline Coupon & Interest rate of issue. \\
\hline Maturity Date & Maturity date of issue. \\
\hline When-Issued Indicator & $\begin{array}{l}\text { Indicator of a trade occurring } \\
\text { before the syndicate settlement date. }\end{array}$ \\
\hline Assumed Settlement Date & $\begin{array}{l}\text { For issues with unknown syndicate } \\
\text { settlement date, a date } 15 \text { business } \\
\text { days after the trade date. }\end{array}$ \\
\hline Trade Date & Date trade was effected. \\
\hline Time of Trade & Time of trade execution. \\
\hline Par Traded & Par amount of trade. \\
\hline Dollar Price (Sale to Customer) & $\begin{array}{l}\text { If trade is a sale to customer, } \\
\text { the dollar price (i.e., trades } \\
\text { at the dealer's ask price). }\end{array}$ \\
\hline Yield (Sale to Customer) & $\begin{array}{l}\text { The yield-to-maturity (not always } \\
\text { reported). }\end{array}$ \\
\hline Dollar Price (Purchase from Customer) & $\begin{array}{l}\text { If trade is purchase from customer, } \\
\text { the dollar price (i.e., trades } \\
\text { at the customer's ask price). }\end{array}$ \\
\hline Yield (Purchase from Customer) & $\begin{array}{l}\text { The yield-to-maturity (not always } \\
\text { reported). }\end{array}$ \\
\hline Dollar Price (Inter-Dealer) & $\begin{array}{l}\text { If the trade was between dealers, } \\
\text { the dollar price. }\end{array}$ \\
\hline Yield (Inter-Dealer Trade) & $\begin{array}{l}\text { The yield-to-maturity (not always } \\
\text { reported.) }\end{array}$ \\
\hline
\end{tabular}




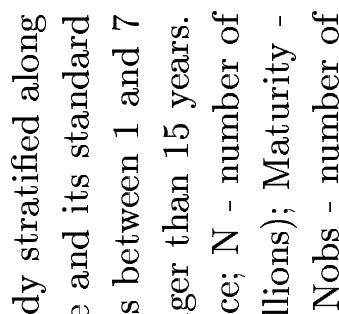

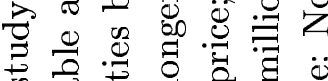

药

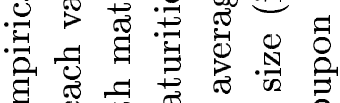

댕

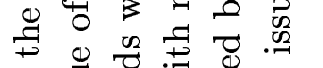

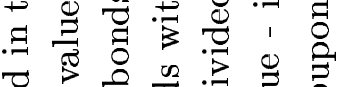

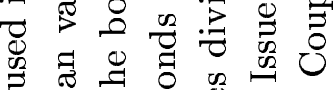

要

क

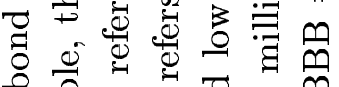

.

. .0.

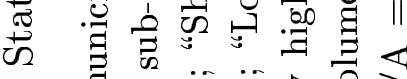

영 द्व

.

.

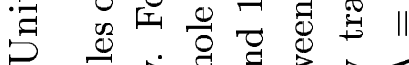

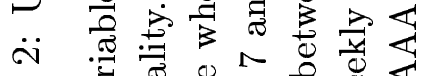

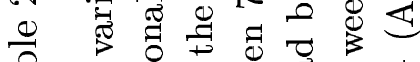

뚱

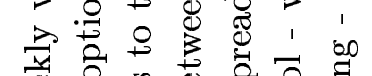

ठ

उ त्ञ

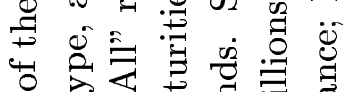

యु

它

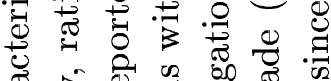

से

త్తુ山

东

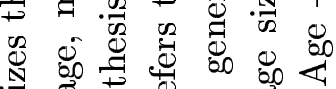

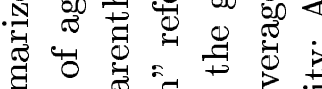

घ

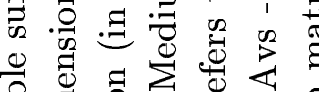

I .9.

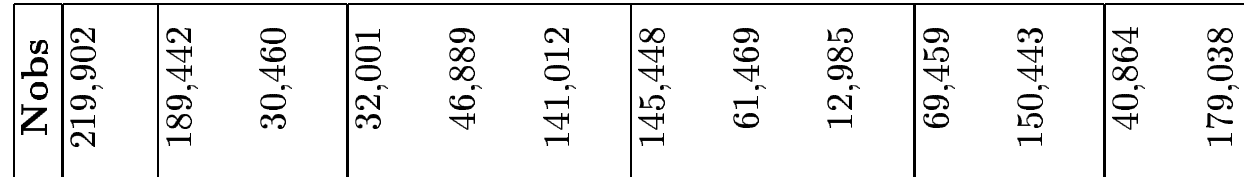

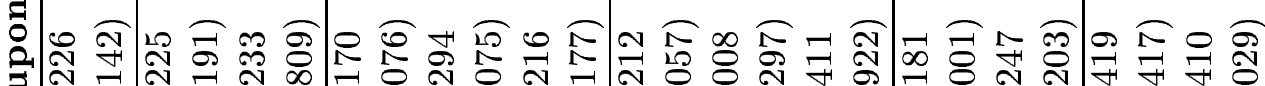
כ

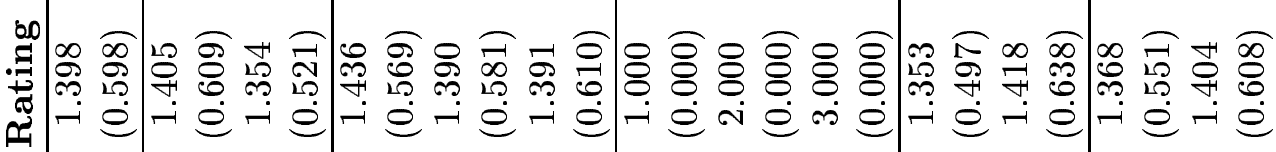

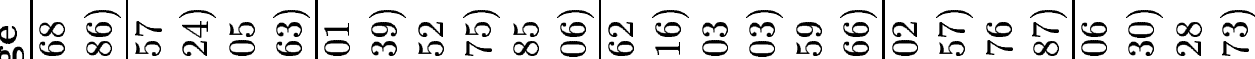

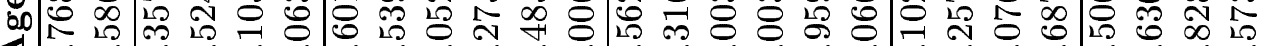
य

is

•

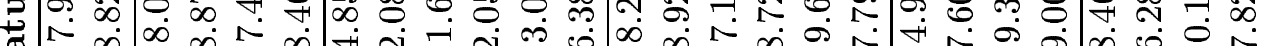

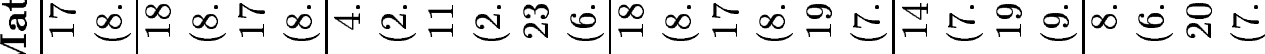

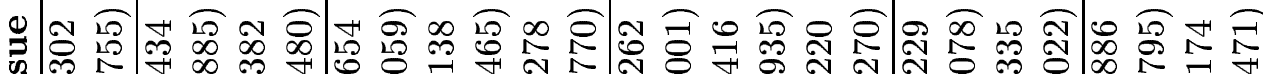
ת. - 0 雨

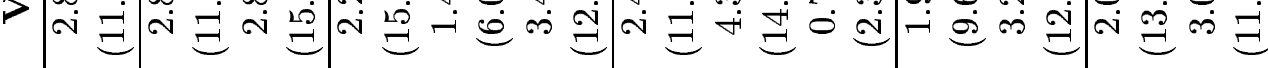
办 年

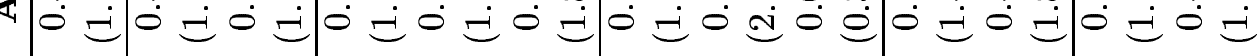

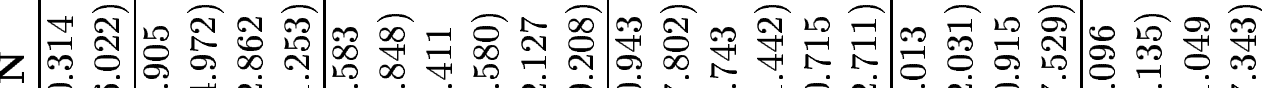

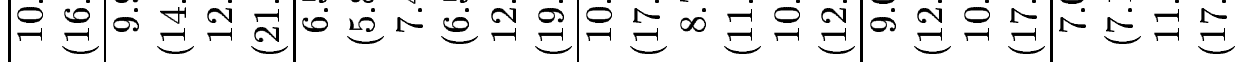

乎 计

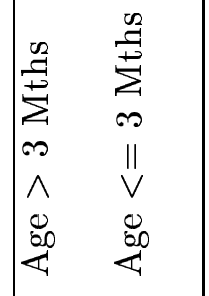
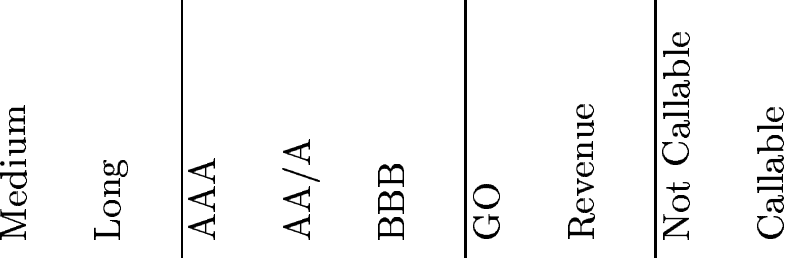

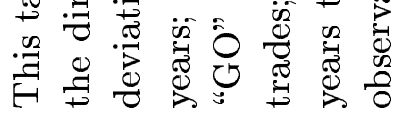




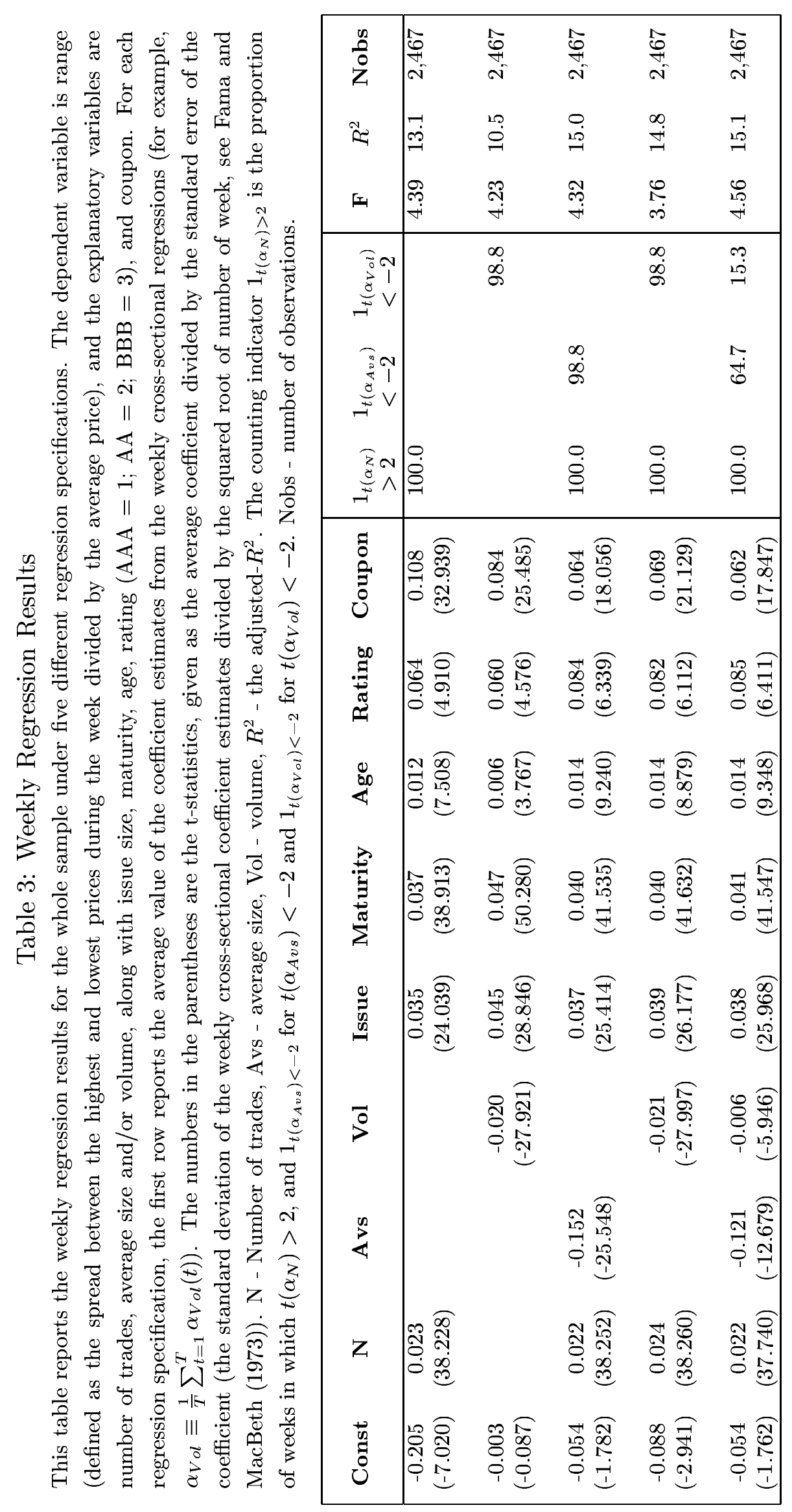




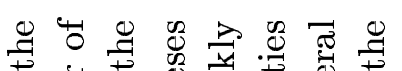

$+$

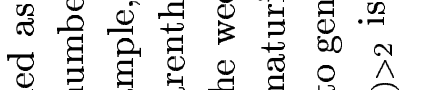

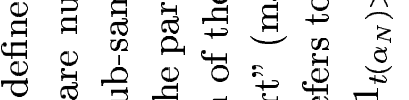

ठ

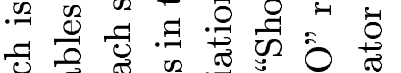

.

范

仓

蛋

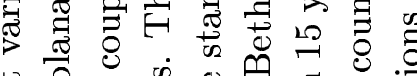

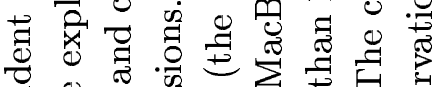

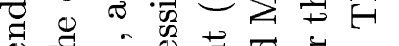

过

ए

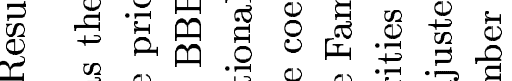

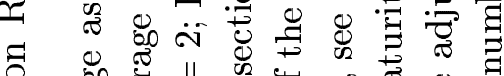

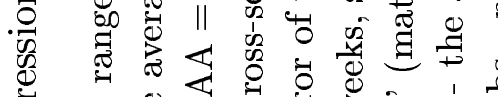

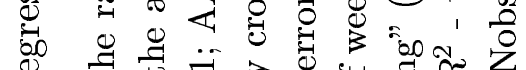

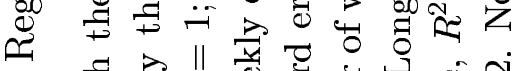

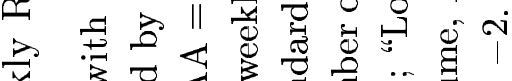

远

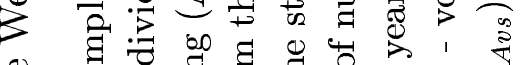

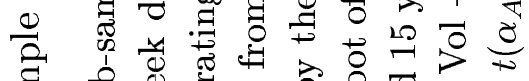

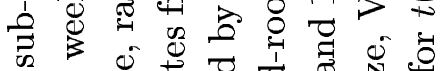

क

की

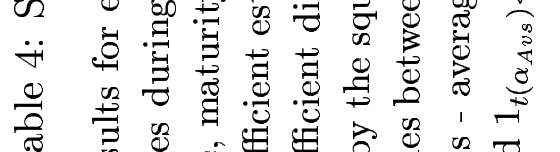

茈

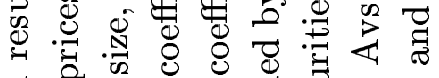

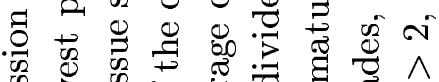
के ర్t $\rightarrow$ क

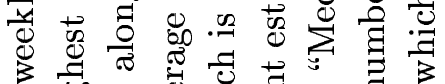
\&. \% 正

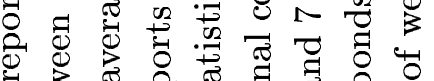

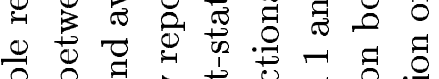
ส

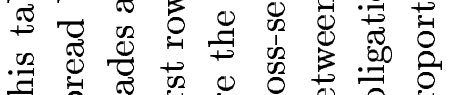

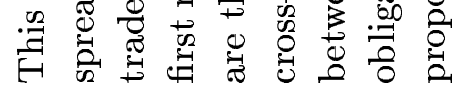

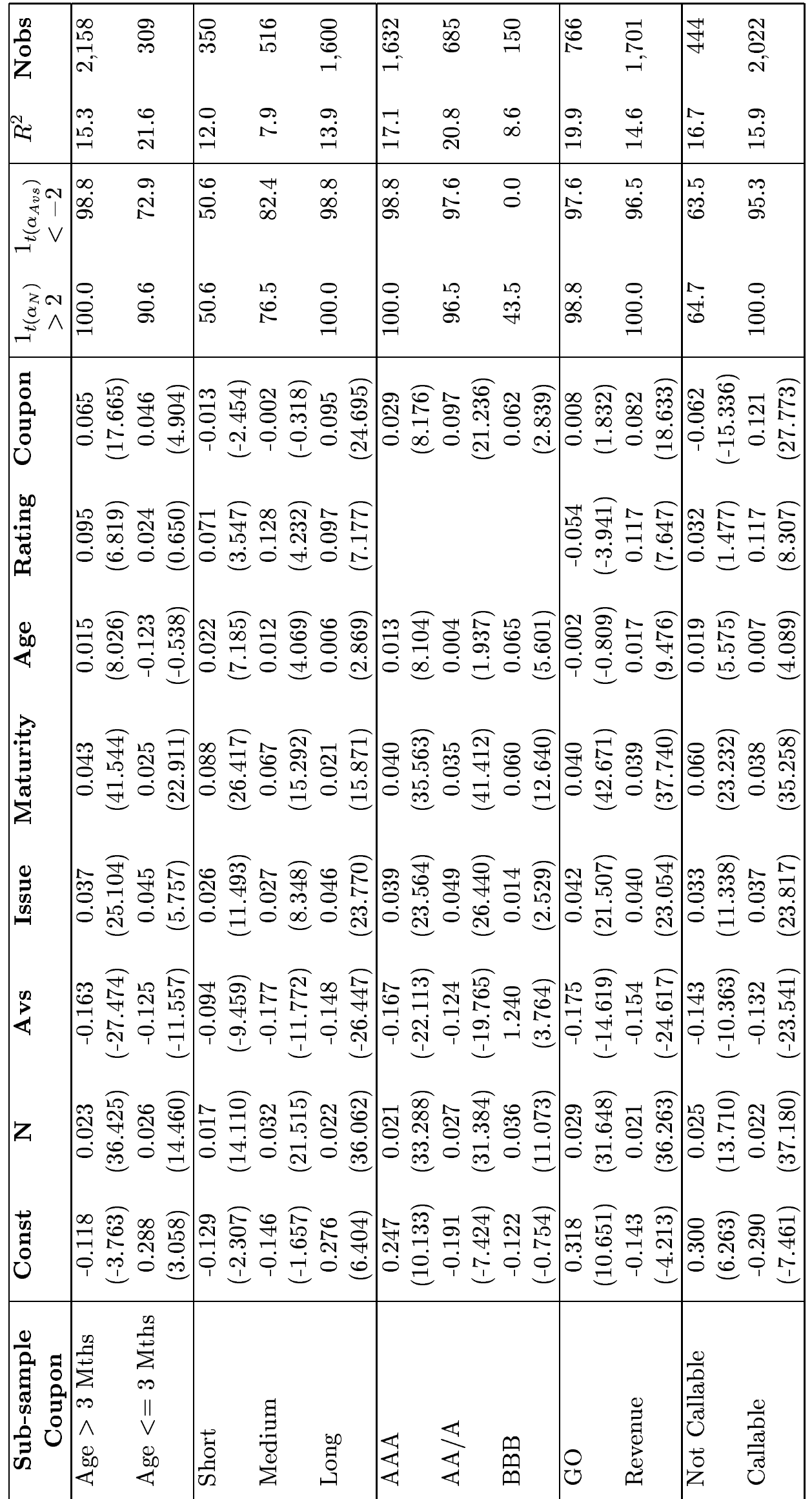




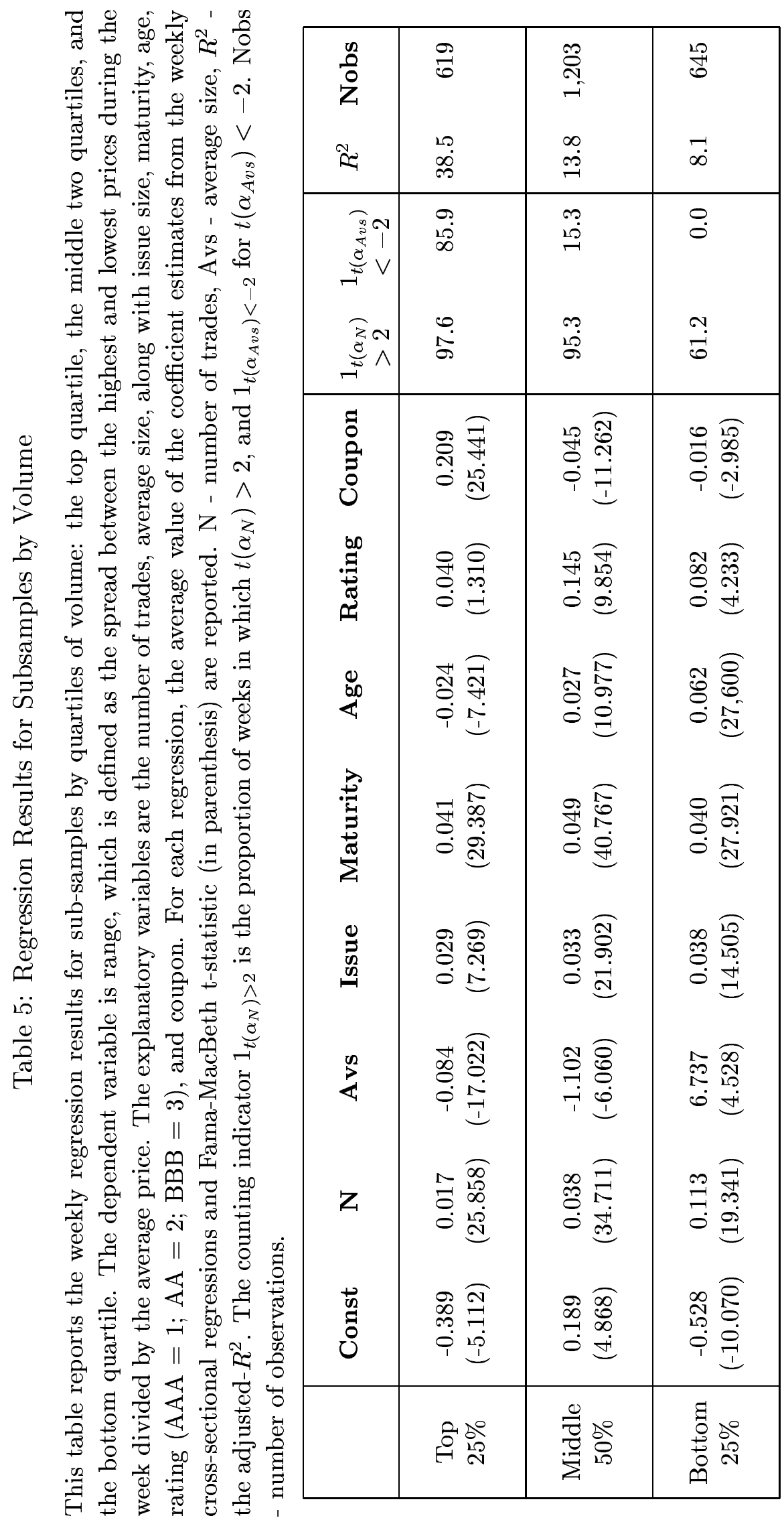




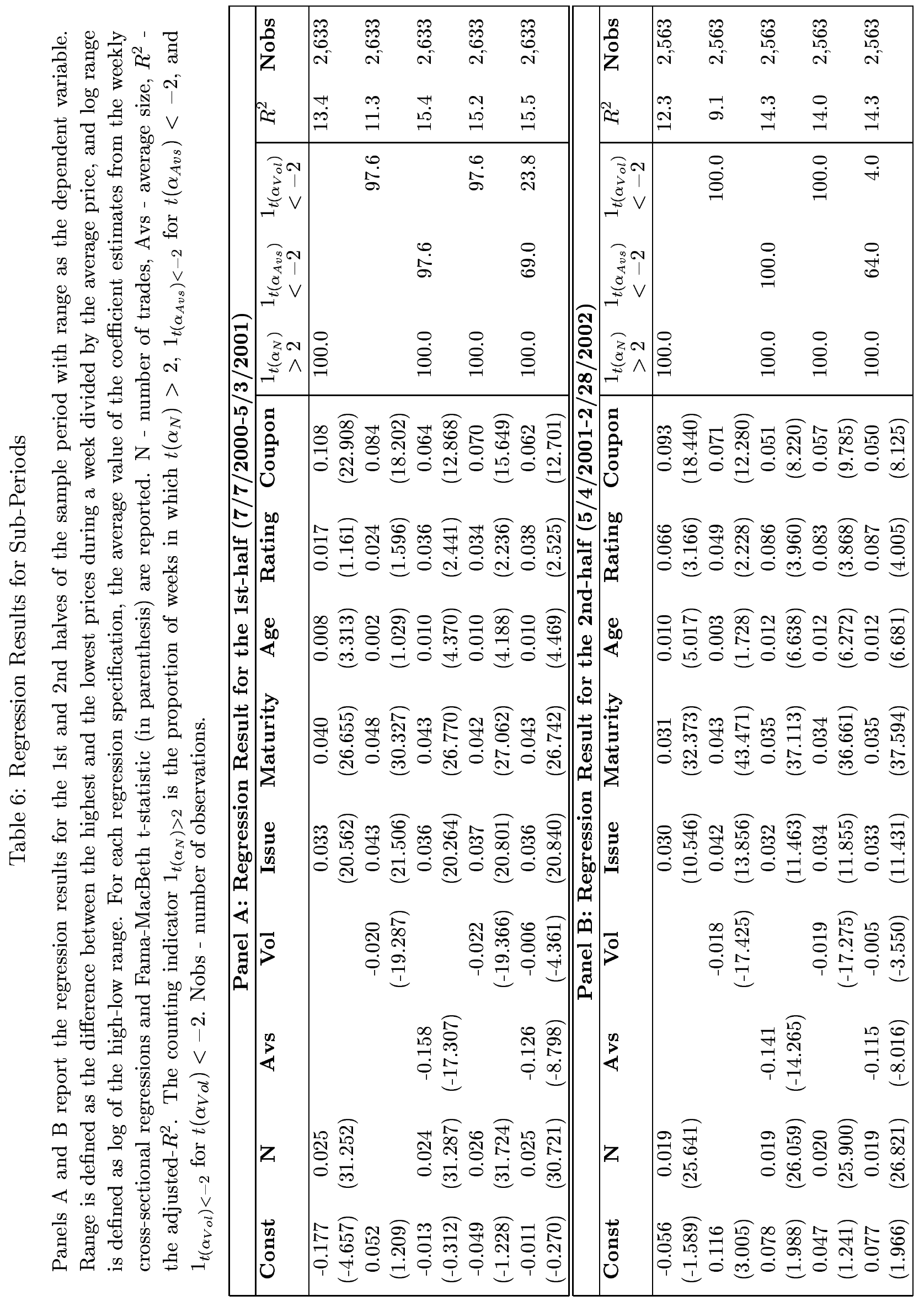




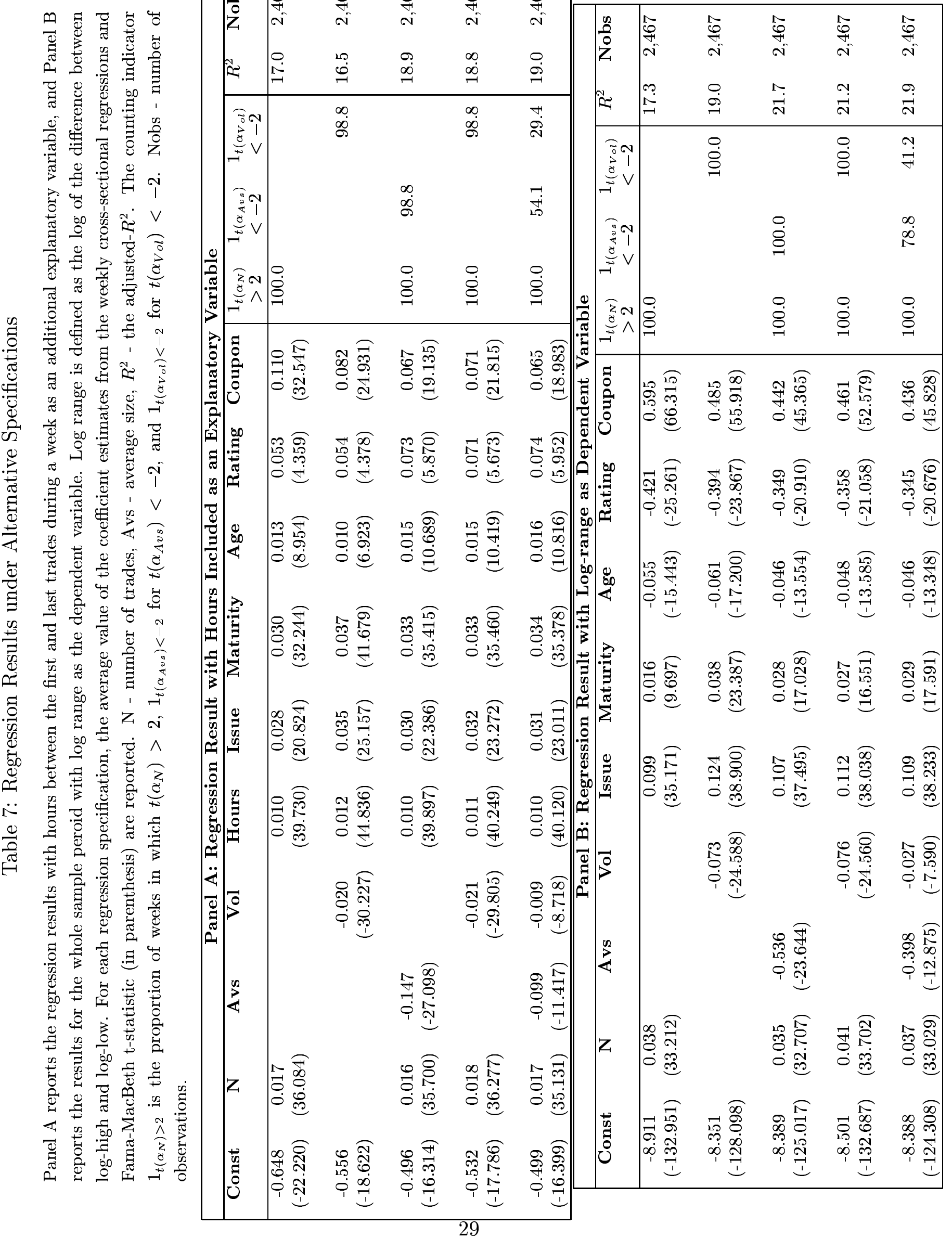


Figure 1: Histograms of Trading Activity

Panel A: Number of Transactions

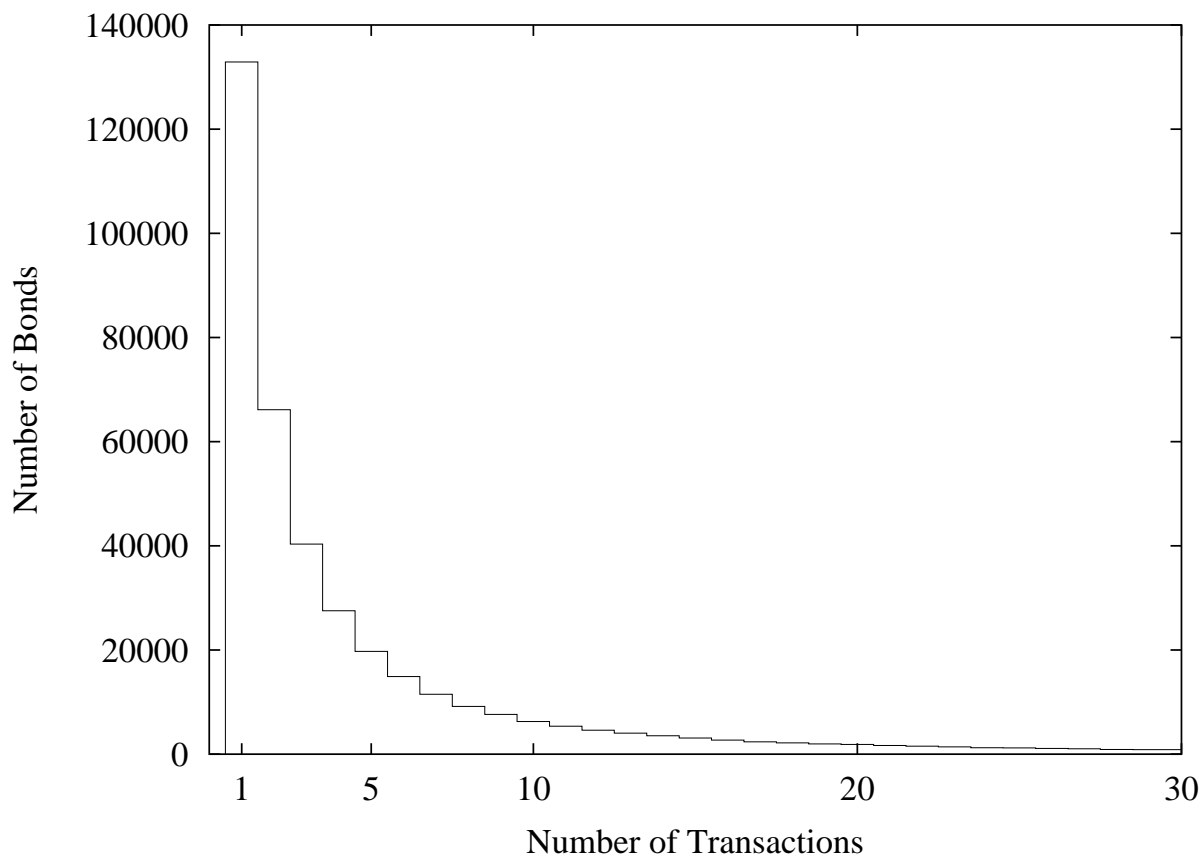

Panel B: Number of Trades Per Week

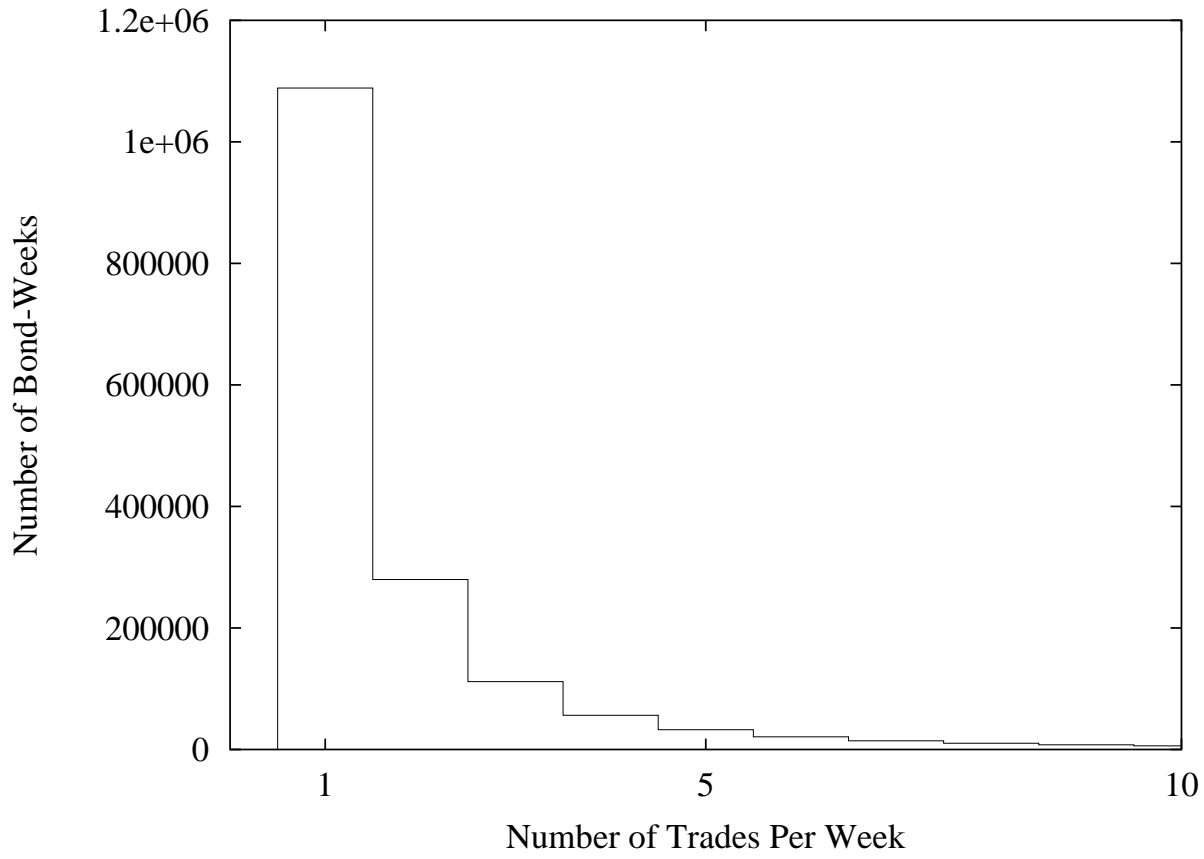

